\title{
Interface-enhanced distillation beyond tradition based on well-arranged graphene membrane
}

\author{
Panpan Zhang ${ }^{1 \dagger}$, Qiang $\mathrm{Xu}^{1 \dagger}$, Qihua Liao ${ }^{1}$, Houze Yao ${ }^{1}$, Debin Wang ${ }^{1}$, Hongya Geng ${ }^{2}$, \\ Huhu Cheng ${ }^{1}$, Chun $\mathrm{Li}^{2}$, Tianbao $\mathrm{Ma}^{1}$ and Liangti $\mathrm{Qu}^{1,2^{*}}$
}

\begin{abstract}
Traditional distillation (TD) is generally an energy-intensive and inefficient process for separation and purification of liquids in chemical industries. Herein, we developed an interface-enhanced distillation (IED) by employing a well-arranged membrane of reduced graphene oxide (rGO) sheet arrays embedded with silicon dioxide nanofibres ( $\mathrm{rGO}$ / $\mathrm{SiO}_{2}$ ) as the evaporation intermediate layer on the liquid surface. This IED enlarges the evaporation surfaces and weakens the intermolecular forces on the liquid/solid/gas interfaces, realizing the fast and even low temperature fraction collection with less energy consumption. The IED delivers evaporation rates $200 \%-300 \%$ times that of TD, meanwhile having an energy saving of $40 \%-60 \%$ and a time saving of $\mathbf{5 0 \% - 7 0 \% ~ f o r ~ d i v e r s e ~ l i q u i d ~ f e e d s . ~ I n ~ a t m o s p h e r i c ~ I E D ~ m a n - ~}$ ner, high boiling point and perishable organics can be collected with high quality at a temperature lower than their boiling points. This IED provides an innovative strategy for highly efficient distillation in chemical industries.
\end{abstract}

Keywords: interface-enhanced distillation, enlarged evaporation surfaces, weakened intermolecular forces, fast evaporation, energy and time savings

\section{INTRODUCTION}

Distillation is key technology in chemical industry to purify and separate liquids from mixtures of components with different boiling points, which is widely utilized in petrifaction, chemical engineering, light industry and so on [1-4]. Traditional distillation (TD) process involves the thermally driven conversion from liquid to gas state at the liquid/gas interface by breaking the intermolecular forces including hydrogen bonds, van der Waals force, and electrostatic energy, and then the condensation of vapor for fraction collection [5-8]. However, TD is an energy-inefficient process with only $5 \%-20 \%$ thermal conversion efficiency and relies heavily on non-renewable energy $[9,10]$, which accounts for more than $50 \%$ energy consumption of the world's chemical industries [11], concomitantly causing severe energy and environmental crisis [12-14]. It has been put in a quandary for effectively improving the distillation efficiency and minimizing the energy consumption.

The evaporation in TD is limited at the planner liquid/ gas interface (Fig. 1a, b), and the escape of vapor must overcome the intensely intermolecular forces within bulk liquid (Fig. 1c) [15-18]. Currently, a variety of previous studies have demonstrated that by rational design of the material structure and management of the interaction between molecules and materials, the evaporation rate can be tailored [15,19]. Yu's group [15] demonstrated that a hierarchically nanostructured gel enabled rapid water diffusion pumping of micron channels and a reduced vaporization enthalpy due to the intermolecular interaction between water molecules and polymeric meshes. Such features endow this hierarchically nanostructured gel with a record high evaporation rate. Zhu's group [20] reported a carbonized mushroom with umbrella-shaped black pileus and porous structure, providing a large surface area for evaporation and minimizing the heat loss for fast evaporation. Herein, we demonstrate an interfaceenhanced distillation (IED) based on a well-arranged membrane with reduced graphene oxide (rGO) sheet

\footnotetext{
${ }^{1}$ Key Laboratory for Advanced Materials Processing Technology, Ministry of Education of China; State Key Laboratory of Tribology, Department of Mechanical Engineering, Tsinghua University, Beijing 100084, China

${ }^{2}$ Department of Chemistry, Tsinghua University, Beijing 100084, China

${ }^{\dagger}$ These authors contributed equally to this work.

* Corresponding author (email: lqu@mail.tsinghua.edu.cn)
} 
arrays embedded with silicon dioxide nanofibres ( $\mathrm{rGO} /$ $\mathrm{SiO}_{2}$ ) as the evaporation intermediate layer on the liquid surface (Fig. 1d), realizing the fast and even low temperature fraction collection. The $\mathrm{rGO} / \mathrm{SiO}_{2}$ membrane allows the adsorptive liquid transport along the aligned lamellar walls (Fig. 1e), inducing the formation of liquid/ solid/gas interfaces and thus greatly enlarging the available area in favor of evaporation compared with TD (Movie S1, an animation showing the IED process). Meantime, the intermolecular forces on liquid/solid/gas interfaces are obviously weakened that facilitates the escape of molecules with a lower energy comsumption. As one example shown in Fig. 1c, f, the bulk water mainly possesses long-range, strong hydrogen bonding interactions [21-23]. After water transports along $\mathrm{rGO} / \mathrm{SiO}_{2}$ lamellar walls with rough surfaces, the increased distance and angle with adjacent water molecules on vertically aligned $\mathrm{rGO} / \mathrm{SiO}_{2}$ wall will cause relatively weak hydrogen bonding interactions [24-26]. As expected, the IED delivers evaporation rates about $200 \%-300 \%$ as high as that of TD with the energy and time savings of up to about $60 \%$ and $70 \%$ for common solvents and specific compounds, respectively. By virtue of atmospheric IED, better-quality fractions are collected from high-boilingpoint and perishable organics at a temperature lower than their boiling points. This innovative IED is expected to largely reduce the energy consumption of global chemical industries.

\section{RESULTS AND DISCUSSION}

\section{Preparation and characterization of the $\mathrm{rGO} / \mathrm{SiO}_{2}$ membrane}

The well-arranged $\mathrm{rGO} / \mathrm{SiO}_{2}$ membrane with aligned lamellar walls was prepared by a directional freeze-drying method [27,28], in which the flexible $\mathrm{SiO}_{2}$ nanofibres with diameters of $300-400 \mathrm{~nm}$ were synthesized by an electrospinning method (Fig. 2a-c) [29]. As shown in Fig. $2 \mathrm{~d}$, a monolith $\mathrm{rGO} / \mathrm{SiO}_{2}$ membrane with a size of $0.5 \mathrm{~m} \times 0.4 \mathrm{~m}$ can be easily manufactured. Cross-sectional scanning electron microscopy (SEM) image shows the long-range vertically aligned lamellar walls of $\mathrm{rGO} / \mathrm{SiO}_{2}$ (Fig. 2e). During the directional freeze-drying process, one-demensional (1D) flexible $\mathrm{SiO}_{2}$ nanofibres are anchored on graphene sheets, assembling into the 2D aligned lamellar walls with tunable channel width from

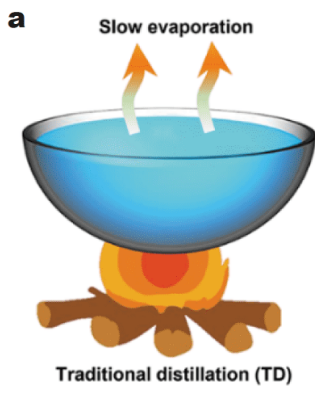

d

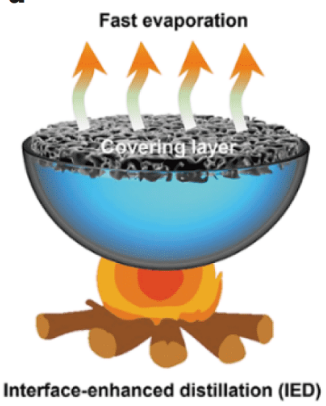

b

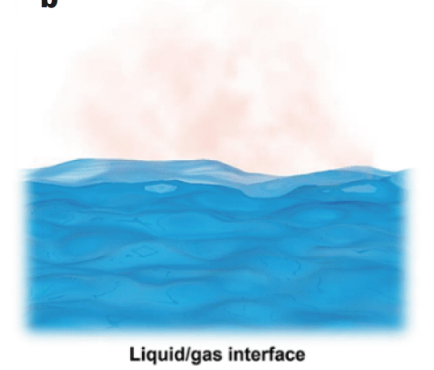

Liquid/gas interface

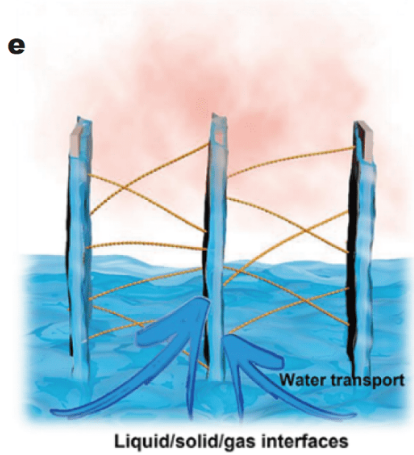

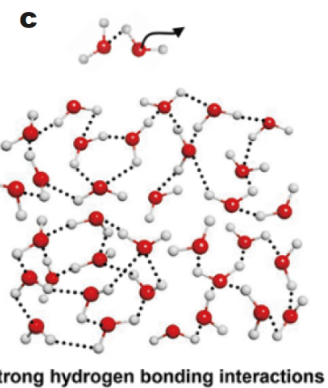

f

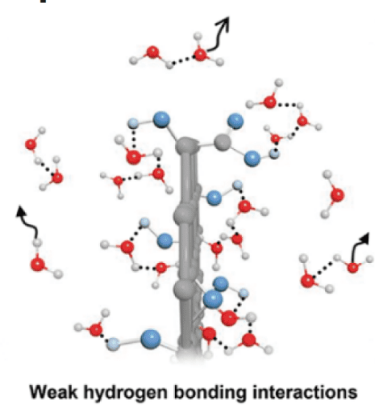

Figure 1 Conceptual diagram. (a, b) Schematic representation of the TD process associated with thermally driven evaporation at the liquid/gas interface. (c) Illustration of the long-range, strong hydrogen bonding interactions in bulk water. (d, e) Schematic representation of the IED process using $\mathrm{rGO} / \mathrm{SiO}_{2}$ membrane with aligned lamellar walls as the evaporation medium layer, which is relevant to the surface-enlarged evaporation at the liquid/solid/gas interfaces with continuous heat supply. (f) The weakened hydrogen bonding interactions on rough $\mathrm{rGO} / \mathrm{SiO}{ }_{2}$ wall surfaces for easy escape of water molecules with lower energy consumption. 

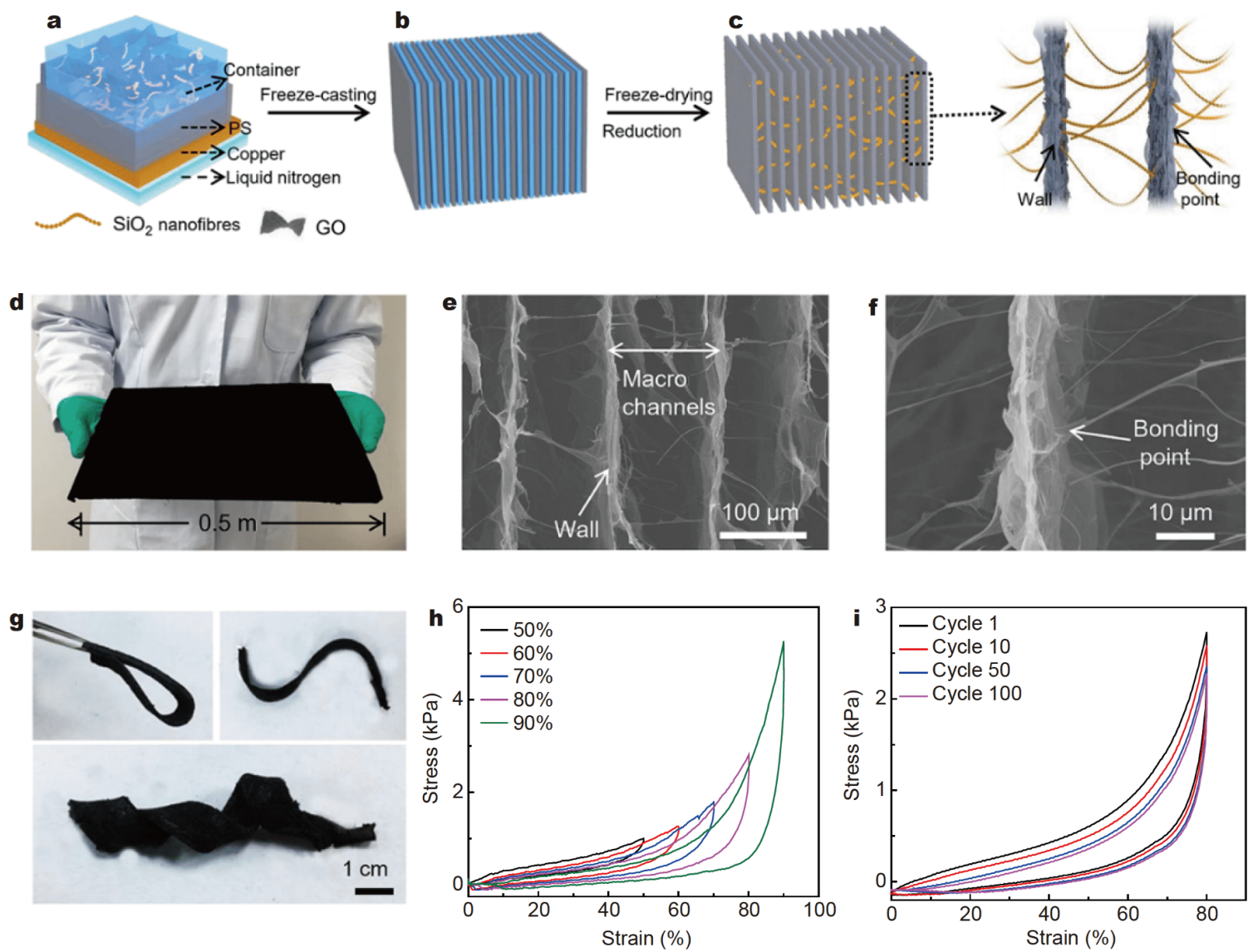

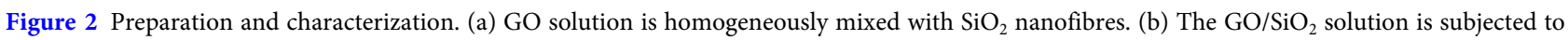
directional freeze-casting to obtain the $\mathrm{GO} / \mathrm{SiO}_{2}$ hydrogel. (c) After freeze-drying and reduction under the vapor of hydrazine hydrate, the $\mathrm{rGO} / \mathrm{SiO}_{2}$ membrane with aligned lamellar walls is obtained. (d) Photograph of a large-scale $\mathrm{rGO} / \mathrm{SiO}_{2}$ membrane with a size of $0.5 \mathrm{~m} \times 0.4 \mathrm{~m}$. (e) Cross-sectional SEM image of $\mathrm{rGO} / \mathrm{SiO}_{2}$ with long-range vertically aligned lamellar walls. (f) The $1 \mathrm{D} \mathrm{SiO}_{2}$ nanofibres are embedded in the $2 \mathrm{D}$ aligned lamellar walls, forming the firm bonding points. (g) Photographs of $\mathrm{rGO} / \mathrm{SiO}_{2}$ membrane subjected to the deformations of bending and twisting. (h) Stress-strain curves of $\mathrm{rGO} / \mathrm{SiO}_{2}$ at different set strains from $50 \%$ to $90 \%$ in water. (i) Cyclic stress-strain curves of $\mathrm{rGO} / \mathrm{SiO}_{2}(=80 \%)$ for 100 cycles in water.

60 to $150 \mu \mathrm{m}$ (Fig. S1a-e). More significantly, the $\mathrm{SiO}_{2}$ nanofibres are well interconnected with the aligned walls to form the strong bonding points, thus effectively endowing the main framework of $\mathrm{rGO} / \mathrm{SiO}_{2}$ membrane with mechanical stability (Fig. 2f) [30]. As a result, the rGO/ $\mathrm{SiO}_{2}$ membrane can be bent, twisted and even compressed to a large degree (Fig. $2 \mathrm{~g}$ ). The $\mathrm{rGO} / \mathrm{SiO}_{2} \mathrm{mem}-$ brane is able to sustain a strain $(\varepsilon)$ deformation of $90 \%$ and keep structural stability after 100 cycles at $\varepsilon=80 \%$ in water (Fig. 2h, i). For pure rGO and $\mathrm{SiO}_{2}$ membranes prepared under the same conditions, irrecoverable deformations occurred at the set strain of 50\% (Fig. S2a, b).

\section{Performance of the IED}

This robust $\mathrm{rGO} / \mathrm{SiO}_{2}$ membrane works as the evaporation intermediate layer on the liquid surface to induce the formation of the liquid/solid/gas interfaces for highly efficient IED (Fig. S3). We first investigated the basic evaporation behavior for common solvents with different latent enthalpies of the liquid-vapor phase change $\left(H_{\mathrm{LV}}\right)$, saturated vapor pressure $\left(P_{\mathrm{V}}\right)$, boiling point $\left(T_{\mathrm{bp}}\right)$ and polarity $(\delta)$ at the ambient condition (temperature $=25^{\circ} \mathrm{C}$, relative humidity $=70 \%$ ), such as $\mathrm{N}, \mathrm{N}$-dimethylformamide (DMF), water, chlorobenzene, and ethanol [31]. The evaporation rate is defined by the Equation (1):

$V=\Delta m / \rho t A$,

where $V\left(\mathrm{~L} \mathrm{~m}^{-2} \mathrm{~h}^{-1}\right)$ is the evaporation rate, $\Delta m$ is the loss of liquid, $\rho\left(\mathrm{kg} \mathrm{m}^{-3}\right)$ is the density, $t(\mathrm{~h})$ is the time of evaporation and $A\left(\mathrm{~m}^{2}\right)$ is the evaporation area. Impressively, by using $\mathrm{rGO} / \mathrm{SiO}_{2}$ membrane as the intermediate layer, all the average evaporation rates are $215 \%-$ $412 \%$ times of those absent of intermediate layers 

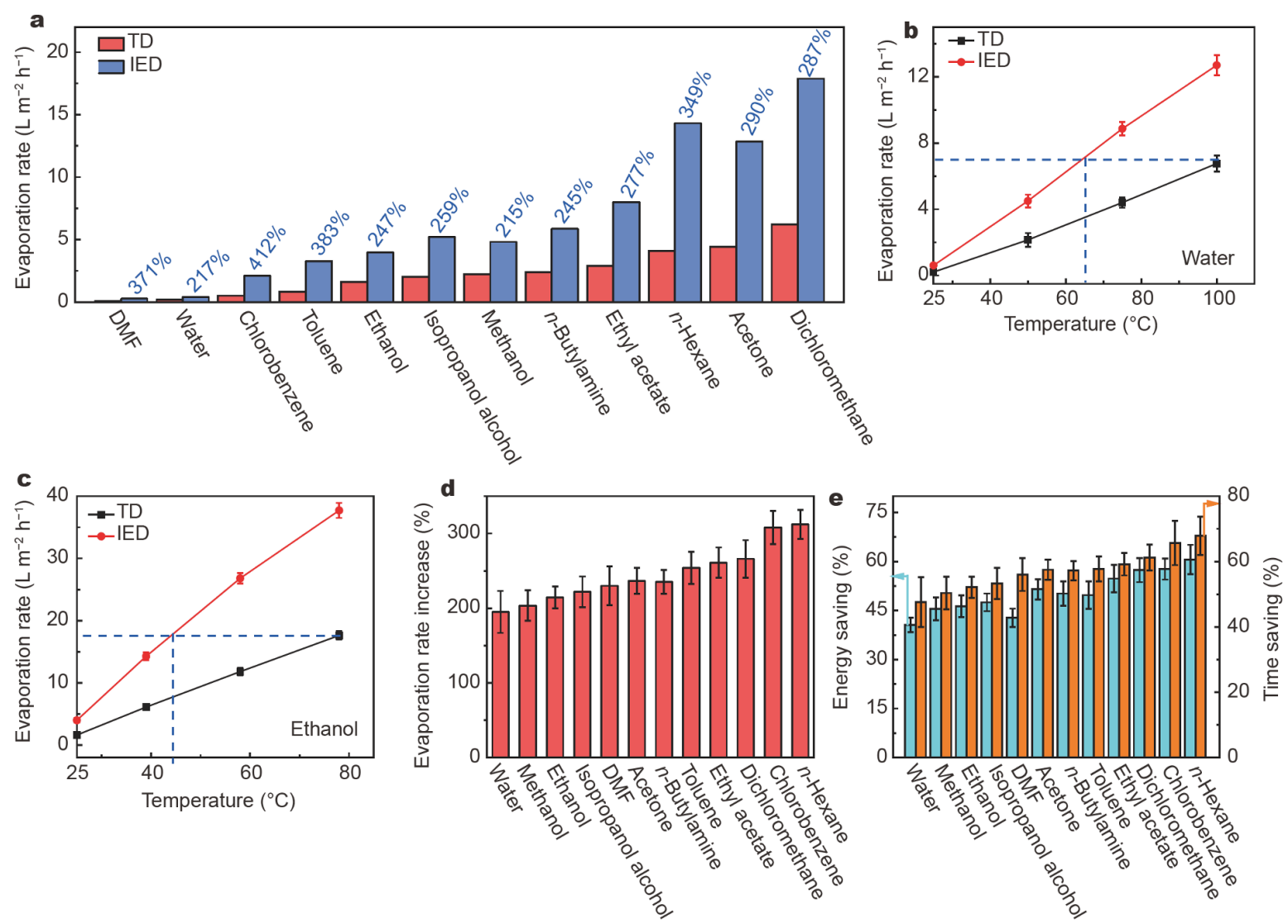

Figure 3 IED performance investigation. (a) Surface evaporation rates of various pure liquids in TD manner and IED mode using $\mathrm{rGO} / \mathrm{SiO}_{2}$ membrane at ambient condition with the temperature of $25^{\circ} \mathrm{C}$ and relative humidity of $70 \%$. Inset percentages in (a) are the evaporation rate increases on $\mathrm{rGO} / \mathrm{SiO}_{2}$ membrane compared with pure liquid. (b) Water evaporation rates in TD and IED modes under different temperatures from 25 to $100^{\circ} \mathrm{C}$. (c) Ethanol evaporation rates in TD and IED modes at temperatures from 25 to $78^{\circ} \mathrm{C}$. (d) Evaporation rate increases of various pure liquids in IED manner, such as water, ethanol, and toluene in contrast with TD at their $T_{\mathrm{bp}}$. (e) Energy and time saving of diverse pure solvents and compounds in the IED mode compared with TD to collect the same amount of products at $T_{\mathrm{bp}}$.

(Fig. 3a). The evaporation rate increases for DMF, chlorobenzene and toluene are higher than other liquids, implying the negative impact of $P_{\mathrm{V}}, \delta$ and $H_{\mathrm{LV}}$ (Table S1 and detailed analyses in Supplementary information) [32]. In this IED mode, the $\mathrm{rGO} / \mathrm{SiO}_{2}$ membrane remains stable in various organic matters for a few months (Fig. S4). The chemical stability of $\mathrm{rGO} / \mathrm{SiO}_{2}$ in IED for solvents (e.g., ethanol, ethyl acetate and DMF) was also verified by energy-dispersive X-ray spectrum (EDS) survey, Fourier transform infrared (FTIR) and X-ray photoelectron spectroscopy (XPS) spectrum (Fig. S5 and the detailed analyses in SI).

These typical solvents and compounds including alkanes, alcohols, ketones and benzenes were tested with IED under different temperatures. The laboratory-built IED system includes a container, an electrical heating sleeve as the heating source, an electronic balance to measure the mass loss and an electricity meter to record the energy consumption (Fig. S6). As temperature varies from $25^{\circ} \mathrm{C}$ to the corresponding $T_{\mathrm{bp}}$, all the evaporation rates for different liquids in IED are much higher than that of TD (Fig. 3b, c), which also means that the IED will allow the effective product collection at a temperature lower than $T_{\mathrm{bp}}$ (dotted line in Fig. 3b, c). The interfacial temperature of the $\mathrm{rGO} / \mathrm{SiO}_{2}$ membrane is almost the same with the temperature of liquid body in the IED mode measured by thermometer (Fig. S7), and the average evaporation rates of diverse liquids in IED increase to $195 \%-312 \%$ compared with TD at $T_{\mathrm{bp}}$ (Fig. $3 \mathrm{~d}$ ). The largely accelerated evaporation rate in IED facilitates the faster fraction collection, as well as much less energy and time consumptions. To obtain the same yield of fractions at $T_{\mathrm{bp}}$ (Table S2), the IED can cut down the expenditure of energy for $40.6 \%-60.2 \%$ and save $48.9 \%$ - 
$67.9 \%$ period of time for the tested solvents and compounds (Fig. 3e). Note that the electricity consumptions of the TD and IED systems are carefully recorded to calculate the energy savings (see SI for detailed analyses).

\section{Mechanism exploration}

The highly efficient IED is mainly ascribed to the enlarged evaporation surfaces and weakened intermolecular forces at the liquid/solid/gas interfaces. Here we chose three representative solvents including water, ethanol and $n$-hexane as examples to explore the mechanism of IED. The optimized water transport channel width of the $\mathrm{rGO} /$ $\mathrm{SiO}_{2}$ membrane is $120 \mu \mathrm{m}$ defined by experimental tests (Fig. S8). The axisymmetric geometric COMSOL model is shown in Fig. 4a, where the phase field method was used to simulate the liquid transport behavior on the channels of $\mathrm{rGO} / \mathrm{SiO}_{2}$ membrane. The amphiphilic $\mathrm{rGO} / \mathrm{SiO}_{2}$ allowed liquid to transport along the aligned lamellar walls and induced the formation of liquid/solid/gas interfaces (Fig. S9). Only part of the channels were filled with liquid and most of the available air space between the aligned lamellar walls of $\mathrm{rGO} / \mathrm{SiO}_{2}$ membrane was effectively exposed for evaporation. In the COMSOL simulations, the agglomerative state of water on the $\mathrm{rGO} / \mathrm{SiO}_{2}$ lamellar walls is larger than that of ethanol and $n$-hexane due to the stronger $\delta$, which is also in accordance with the optical microscopy observations with larger amount of adsorptive water on the $\mathrm{rGO} / \mathrm{SiO}_{2}$ surface (Fig. $4 \mathrm{~b}$ and Figs S10, S11).

On the other hand, the molecular dynamics (MD) simulation reveals the intermolecular force within liquid in TD and IED modes [33-38]. After equilibration at $T_{\mathrm{bp}}$, the $\mathrm{rGO} / \mathrm{SiO}_{2}$ was hydrated and surrounded by liquid molecules (Fig. 4c and Figs S12-S14). The intermolecular energy of liquid $\left(E_{\text {inter }}(\mathrm{l})\right)$, including hydrogen bonds, van der Waals force, and electrostatic energy, was defined by Equation (2) [36]:

$E_{\text {inter }}(1)=\sum_{i<j}^{N}\left\{4 \varepsilon_{i j}\left[\left(\frac{\sigma_{i j}}{r_{i j}}\right)^{12}-\left(\frac{\sigma_{i j}}{r_{i j}}\right)^{6}\right]+\frac{q_{i} q_{j}}{4 \pi \varepsilon_{0} r_{i j}}\right\}$,

where $\varepsilon_{i j}, \sigma_{i j}, r_{i j}$ and $\varepsilon_{0}$ are the Lennard-Jones (LJ) energy parameter, LJ size parameter, the distance between atoms $i$ and $j$, and the vacuum permittivity, respectively. Benefiting from the enlarged rough evaporation surfaces and oxygen-containing functional groups of $\mathrm{rGO} / \mathrm{SiO}_{2}$, the
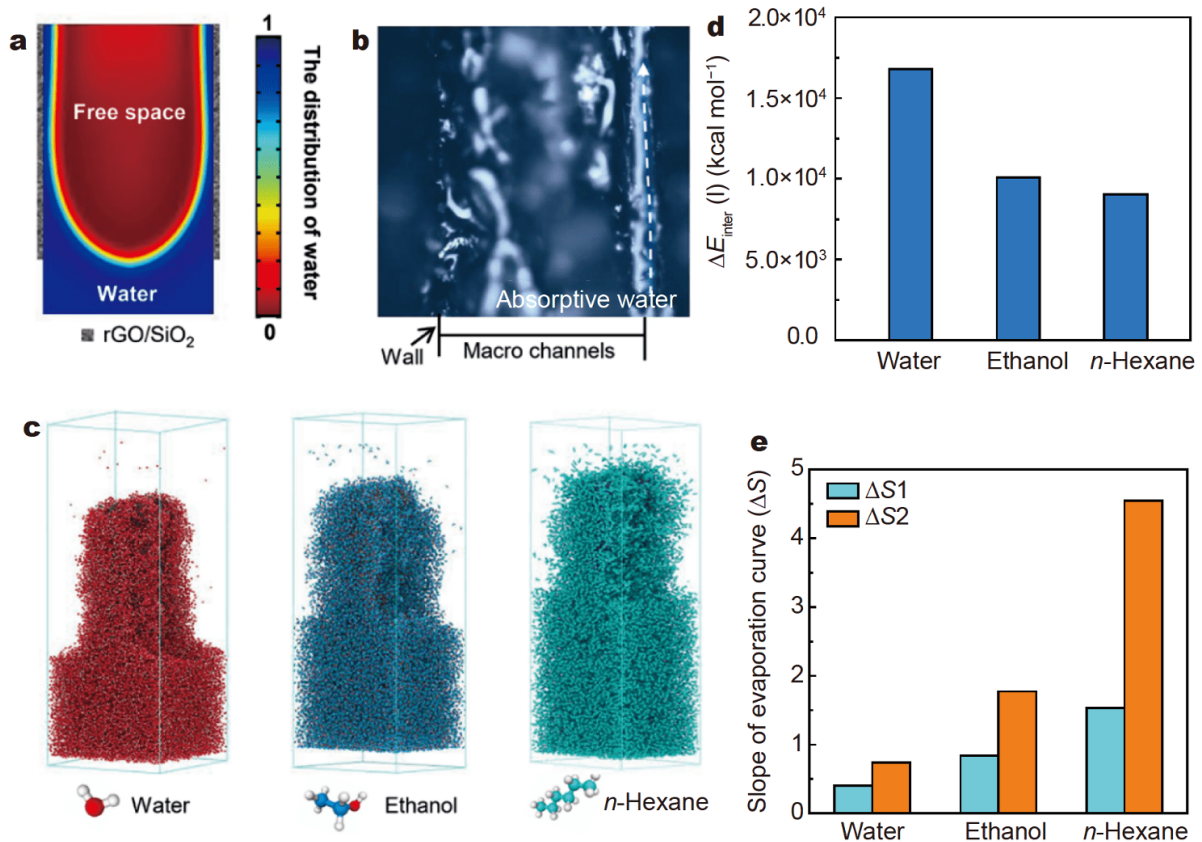

Figure 4 Mechanism exploration of IED. (a) COMSOL simulation results of water transport pathway in the channel of the $\mathrm{rGO} / \mathrm{SiO}_{2} \mathrm{membrane}$. The modeled structure is built according to the axisymmetric geometric principle with the optimized channel width of $120 \mu \mathrm{m}$. (b) Optical microscopy images of water on the $\mathrm{rGO} / \mathrm{SiO}_{2}$ membrane. (c) Snapshots of water, ethanol and $n$-hexane evaporation in the IED mode after equilibration at $T_{\text {bp }}$ in the MD simulation. The IED shows enlarged evaporation surface. (d) The decreased intermolecular energy $\left(E_{\text {inter }}(1)\right)$ of liquids on the $\mathrm{rGO}_{\mathrm{SiO}}$ surface in IED mode compared with bulk liquid in the TD system after equilibration in the MD. (e) The slopes $(\Delta S)$ of evaporation curves versus time for water, ethanol and $n$-hexane vapor molecules in TD and IED modes after equilibration at $T_{\mathrm{bp}}$ in the MD simulations, respectively. $\Delta S 1$ and $\Delta S 2$ are named for bulk liquid in TD and liquid on the $\mathrm{rGO} / \mathrm{SiO}_{2}$ membrane in the IED mode. 
consecutive network of the intermolecular forces in liquid on $\mathrm{rGO} / \mathrm{SiO}_{2}$ is disturbed and the $r_{i j}$ of the molecules on $\mathrm{rGO} / \mathrm{SiO}_{2}$ surface is increased $[5,39,40]$, resulting in the decreased intermolecular energy (Fig. 4d). Especially for water with strong hydrogen bonding interactions, the number of hydrogen bonds in bulk water is 2.49 times as high as that of water on the $\mathrm{rGO} / \mathrm{SiO}_{2}$ membrane (Fig. S15). The $H_{\mathrm{LV}}$ of liquid is mainly related to the intermolecular energy, which is written as Equation (3) [15,36]:

$H_{\mathrm{LV}}=-E_{\text {inter }}(1)+N k_{\mathrm{B}} T$,

where $N$ is the number of liquid molecules and $k_{\mathrm{B}}$ is the Boltzmann constant. Consequently, the decreased intermolecular energy of liquids on the $\mathrm{rGO} / \mathrm{SiO}_{2}$ surface induces reduced $H_{\mathrm{LV}}$ compared with bulk liquid. As demonstrated in differential scanning calorimetry (DSC), the $H_{\mathrm{LV}}$ of liquids on $\mathrm{rGO} / \mathrm{SiO}_{2}$ was lower than that of bulk liquids for water, ethanol and $n$-hexane, respectively (Table S3), promoting fast liquid evaporation in the IED mode. In the MD simulation (Movies S2-S7), the slopes of evaporation curves versus time indicate the evaporation rates named as $\Delta S 1$ and $\Delta S 2$ for bulk liquid in TD and liquid on the $\mathrm{rGO} / \mathrm{SiO}_{2}$ membrane in the IED mode (Fig. S16). Notably, water on the $\mathrm{rGO} / \mathrm{SiO}_{2}$ surface possesses higher agglomerative state and stronger intermolecular force compared with ethanol and $n$-hexane. After equilibration at $T_{\mathrm{bp}}$, the $\Delta S 2$ in IED is $185 \%, 211 \%$ and $294 \%$ times of $\Delta S 1$ in TD mode (Fig. 4e), respectively, demonstrating similar increase trend with the experimental results.

In the IED system, the well-arranged $\mathrm{rGO} / \mathrm{SiO}_{2}$ membrane with aligned lamellar walls works as the macroporous intermediate layer on liquid surface for accelerated evaporation. The $\mathrm{rGO} / \mathrm{SiO}_{2}$ is rich in oxygencontaining functional groups [41] and favorable for liquid spreading to form the enlarged liquid/solid/gas interfaces, in which the intermolecular forces cannot persist to the extent as found in bulk liquid $[42,43]$. Optical microscopy images of DMF, toluene and ethyl acetate reveal the similar enlarged evaporation surface on the $\mathrm{rGO} / \mathrm{SiO}_{2}$ membrane (Fig. S17), and the corresponding evaporation rates in IED are $203 \%-308 \%$ as high as that in TD mode (Fig. 3d). The enlarged evaporation surface and weakened intermolecular forces at the liquid/solid/gas interfaces function together to accelerate the evaporation in IED. By contrast, the cellular-structured $\mathrm{rGO} / \mathrm{SiO}_{2}$ film was measured in IED with a lower evaporation rate than that of the $\mathrm{rGO} / \mathrm{SiO}_{2}$ membrane with vertically aligned lamellar walls (Fig. S18a) [44]. The vapor escape route was blocked on the cellular-structured $\mathrm{rGO} / \mathrm{SiO}_{2}$ film as shown in the optical microscopy observation (Fig. S18b, c). Similarly, the IED performance by using the well-arranged $\mathrm{rGO} / \mathrm{SiO}_{2}$ membrane is better than that of other porous materials with cellular or layer-by-layer structures, such as polyimide (PI) film, carbonized polyurethane (PU) foam and rGO film (Fig. S19).

\section{Separation and purification of liquid mixtures}

The IED system was then investigated to separate and purify liquid mixtures with different $T_{\mathrm{bp}}$, such as polar mixtures (e.g., ethanol/water, water/DMF, and 1,4-dioxane/chlorobenzene), high-boiling-point solutions (e.g., $\mathrm{DMF} /$ dimethyl sulfoxide (DMSO), DMSO/N,N-dimethyl formamide (NMP), and ethylene glycol/NMP) and perishable organics (e.g., ethyl acetoacetate/DMSO and partially oxidized aniline) for fast fraction collection. We designed an open IED apparatus $(250 \mathrm{~mL})$ that allowed the $\mathrm{rGO} / \mathrm{SiO}_{2}$ intermediate layer (diameter $=70 \mathrm{~mm}$, thickness $=2 \mathrm{~mm}$ ) standing above the liquid surface (Fig. 5a and Fig. S20). As expected, at the steam temperature of $T_{\mathrm{bp}}$, the IED exhibited evaporation rates about $187 \%-284 \%$ as high as TD for fraction collection from all the mixtures (Fig. 5b and Fig. S21a, b). The resulting energy and time saving for the separation and purification mixtures in IED at $T_{\mathrm{bp}}$ are $40.6 \%-57.2 \%$ and $46.0 \%-$ $64.8 \%$, respectively (Fig. S21c and Table S4). This effective IED based on the well-arranged $\mathrm{rGO} / \mathrm{SiO}_{2}$ membrane indeed enables fast distillation with much less energy and time.

Remarkably, at a steam temperature lower than their $T_{\mathrm{bp}}$ in IED, there is the same amount of fraction collection with an $11-39^{\circ} \mathrm{C}$ temperature decrease compared with TD (Fig. 5c, d and Fig. S22). The saturated vapor pressure $\left(P_{\mathrm{V}}\right)$ at different temperatures was defined by the Clausius-Claperon equation, which is written as [5]:

$\frac{\mathrm{d} \ln P_{\mathrm{V}}}{\mathrm{d}(1 / T)}=\frac{-H_{\mathrm{LV}}}{R Z_{\mathrm{LV}}}$

where $R$ is the universal gas constant $\left(8.314 \mathrm{~J} \mathrm{~K}^{-1} \mathrm{~mol}^{-1}\right)$, and $Z_{\mathrm{LV}}$ is the compressibility factor difference between saturated vapor and liquid. In Equation (4), $Z_{\mathrm{LV}}$ can be approximated as a constant for the same liquid and the $P_{\mathrm{V}}$ is mainly influenced by $H_{\mathrm{LV}}$. The latent enthalpies of the liquid-vapor phase change of pure liquid and liquid on $\mathrm{rGO} / \mathrm{SiO}_{2}$ are named as $H_{\mathrm{LV} 1}$ and $H_{\mathrm{LV} 2}$, respectively. In the IED mode, the weakened intermolecular force of liquids on the $\mathrm{rGO} / \mathrm{SiO}_{2}$ membrane induces the reduced $H_{\mathrm{LV} 2}$. As shown in the DSC measurement, the $H_{\mathrm{LV} 2}$ in IED is $7 \%-29 \%$ lower than $H_{\mathrm{LV} 1}$ in TD for the tested 

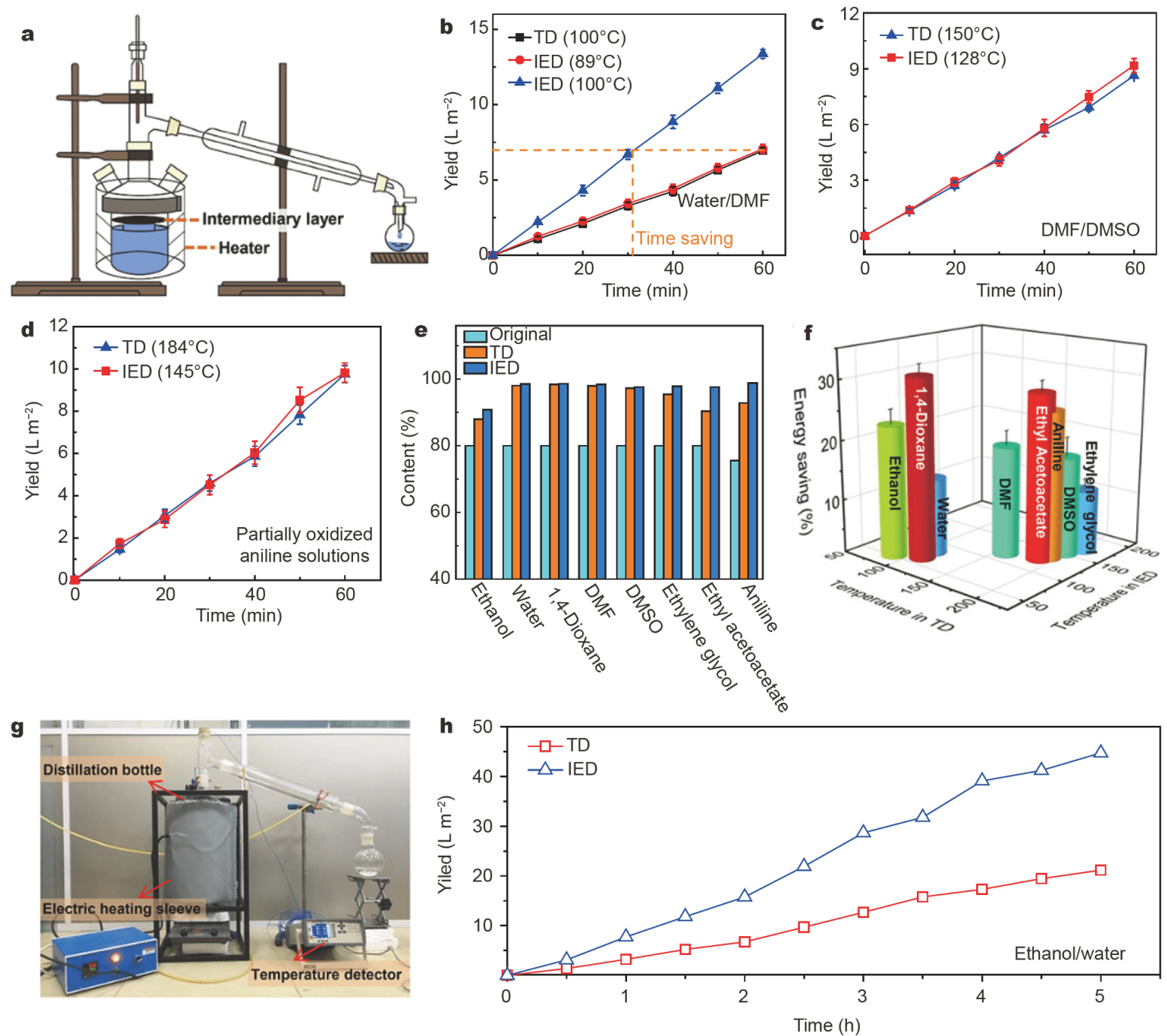

Figure 5 IED for the separation and purification of liquid mixtures. (a) Laboratory-built IED system using the $\mathrm{rGO} / \mathrm{SiO}_{2} \mathrm{membrane}$ as the evaporation medium layer on liquid surface and electrical heating sleeve as the heater. (b) The water yield in TD and IED from the water/DMF mixture $(4: 1, v / v)$. (c, d) The DMF and aniline yield fractions from high-boiling-point solutions (DMF/DMSO, 4:1, v/v) and partially oxidized aniline reagent by TD and IED under different temperatures. (e) The content of the targeted solvents and compounds in original liquid mixtures, and the collected fractions by TD at $T_{\mathrm{bp}}$ and IED at temperature lower than $T_{\mathrm{bp}}$, respectively. Expect for partially oxidized aniline solution, the volume ratio of the liquid mixture $(m / n)$ is $4: 1$, where $m$ is the targeted substance and $n$ is the other solvent. (f) Energy saving for separation and purification of various liquids in IED at the temperature lower than their $T_{\mathrm{bp}}$ when compared with TD. (g) The scaling up IED system of $0.4 \mathrm{~m} \times 0.4 \mathrm{~m} \times 1.3 \mathrm{~m}$. (h) The ethanol yields by TD and IED from ethanol/water mixture $(4: 1, v / v)$ in the large scale IED system at $T_{\mathrm{bp}}\left(78^{\circ} \mathrm{C}\right)$.

liquids, such as ethanol, water, 1,4-dioxane, and DMF (Fig. S22 and Table S5). According to Equation (4), the reduced $H_{\mathrm{LV} 2}$ will largely increase the $P_{\mathrm{V}}$ on the $\mathrm{rGO} / \mathrm{SiO}_{2}$ surface in IED compared with TD, which also mean that at a temperature lower than their $T_{\mathrm{bp}}$ in the TD mode, the $P_{\mathrm{V}}$ in the IED system can reach to the value close to the atmospheric pressure, thus realizing the low temperature fraction collection (Fig. S23).

This low-temperature IED presents great potential for high-quality fraction production with much less energy consumption, especially for the separation and purification of high- $T_{\mathrm{bp}}$ liquid mixture and perishable organics. For example, the collection of ethyl acetoacetate or aniline by IED is at the steam temperature of 137 or $145^{\circ} \mathrm{C}$, which are 43 and $39^{\circ} \mathrm{C}$ lower than their $T_{\mathrm{bp}}$ in TD system of 180 and $184^{\circ} \mathrm{C}$, respectively. As a result, the purity of ethyl acetoacetate or aniline in IED is $97.6 \%$ and $98.4 \%$, much higher than that in TD with the value of $90.3 \%$ and $92.8 \%$ confirmed by gas chromatography (Fig. 5e and Figs S24, S25). Moreover, the purity of other products 
collected at the temperature lower than $T_{\mathrm{bp}}$ in IED also exhibits comparable purity with TD mode (Figs S26-S31). This low-temperature and highly efficient IED do a favour to save ca. $10.9 \%-30.8 \%$ energy consumption for all of the mixture distillation (Fig. 5f). More importantly, the fraction collection at a temperature lower than $T_{\mathrm{bp}}$ in the IED system also shows the importance to reduce heat loss, improve energy conversion efficiency, as well as cut down the cost of equipment investment. Notably, the $\mathrm{rGO} / \mathrm{SiO}_{2}$ membrane presents excellent mechanical property in liquid. After long-term cyclic tests, it can still maintain structural stability in organic media (Fig. S32).

The scaled-up IED system was also manufactured to demonstrate the feasibility for high output of product from the ethanol/water mixtures $(4: 1, v / v)$. The $\mathrm{rGO} / \mathrm{SiO}_{2}$ membrane with the diameter of $0.35 \mathrm{~m}$ was used with the initial liquids of $65 \mathrm{~L}$ in the open distillation reactor (Fig. 5g). Under continuous condensation, ca. $44.7 \mathrm{~L} \mathrm{~m}^{-2}$ ethanol was obtained within $5 \mathrm{~h}$ in the IED system at the steam temperature of $78^{\circ} \mathrm{C}$, about 2.1 times of that in TD with the output of ca. $21.1 \mathrm{~L} \mathrm{~m}^{-2}$ (Fig. 5h), well proving the effectiveness and durability of IED in large scale for the separation of liquid mixtures.

\section{CONCLUSIONS}

In summary, we demonstrated an efficient IED by using the well-arranged $\mathrm{rGO} / \mathrm{SiO}_{2}$ membrane as the evaporation intermediate layer on the liquid surface. Unlike TD model, the IED takes full use of enlarged evaporation surfaces and weakened intermolecular forces on the liquid/solid/gas interfaces, thus accelerating about 200\%$300 \%$ evaporation rates of diverse solvents and compounds. The concomitant energy and time consumption in the IED system can be decreased by up to about $60 \%$ and $70 \%$, respectively. More importantly, the developed IED system realizes the production of better quality for high-boiling-point and perishable organics at a temperature lower than their $T_{\mathrm{bp}}$. Such efficiently and widely applicable IED strategy shows great potential to boost the development of other distillation systems, such as rectification, flash distillation or multistage distillation processes with great global merits of energy and time savings.

Received 13 April 2020; accepted 1 June 2020;

published online 28 August 2020

1 Neumann O, Neumann AD, Tian S, et al. Combining solar steam processing and solar distillation for fully off-grid production of cellulosic bioethanol. ACS Energy Lett, 2017, 2: 8-13

2 Laird T. Advanced distillation technologies: Design, control and applications. Org Process Res Dev, 2013, 17: 1074

3 Sholl DS, Lively RP. Seven chemical separations to change the world. Nature, 2016, 532: 435-437

4 Subramani A, Jacangelo JG. Emerging desalination technologies for water treatment: A critical review. Water Res, 2015, 75: 164187

5 Neumann O, Neumann AD, Silva E, et al. Nanoparticle-mediated, light-induced phase separations. Nano Lett, 2015, 15: 7880-7885

6 Earle MJ, Esperança JMSS, Gilea MA, et al. The distillation and volatility of ionic liquids. Nature, 2006, 439: 831-834

7 Yang $\mathrm{H}$, Yang L, Wang $\mathrm{H}$, et al. Covalent organic framework membranes through a mixed-dimensional assembly for molecular separations. Nat Commun, 2019, 10: 2101

8 Ewell RH, Harrison JM, Berg L. Azeotropic distillation. Ind Eng Chem, 1944, 36: 871-875

9 Reddy CCS, Fang Y, Rangaiah GP. Improving energy efficiency of distillation using heat pump assisted columns. Asia-Pac J Chem Eng, 2014, 9: 905-928

10 Saidur R, Elcevvadi ET, Mekhilef S, et al. An overview of different distillation methods for small scale applications. Renew Sustain Energy Rev, 2011, 15: 4756-4764

11 Olujic Z, Sun L, Gadalla M, et al. Enhancing thermodynamic efficiency of energy intensive distillation columns via internal heat integration. Chem Biochem Eng Q, 2008, 22: 383-392

12 Gutiérrez-Guerra R, Segovia-Hernández JG, Hernández S. Reducing energy consumption and $\mathrm{CO}_{2}$ emissions in extractive distillation. Chem Eng Res Des, 2009, 87: 145-152

13 Kiss AA, Flores Landaeta SJ, Infante Ferreira CA. Towards energy efficient distillation technologies-Making the right choice. Energy, 2012, 47: 531-542

14 Abdehagh N, Tezel FH, Thibault J. Separation techniques in butanol production: Challenges and developments. Biomass Bioenergy, 2014, 60: 222-246

15 Zhao F, Zhou X, Shi Y, et al. Highly efficient solar vapour generation via hierarchically nanostructured gels. Nat Nanotech, 2018, 13: 489-495

16 Kumar R, Schmidt JR, Skinner JL. Hydrogen bonding definitions and dynamics in liquid water. J Chem Phys, 2007, 126: 204107

17 Israelachvili JN. Intermolecular and Surface Forces. Salt Lake City: Academic Press, 2015

18 Byl O, Liu JC, Wang Y, et al. Unusual hydrogen bonding in waterfilled carbon nanotubes. J Am Chem Soc, 2006, 128: 12090-12097

19 Zhao F, Guo Y, Zhou X, et al. Materials for solar-powered water evaporation. Nat Rev Mater, 2020, 5: 388-401

$20 \mathrm{Xu} \mathrm{N}, \mathrm{Hu} \mathrm{X}, \mathrm{Xu} \mathrm{W}$, et al. Mushrooms as efficient solar steamgeneration devices. Adv Mater, 2017, 29: 1606762

21 Winter B, Aziz EF, Hergenhahn U, et al. Hydrogen bonds in liquid water studied by photoelectron spectroscopy. J Chem Phys, 2007, 126: 124504

22 Matsumoto M, Ohmine I. A new approach to the dynamics of hydrogen bond network in liquid water. J Chem Phys, 1996, 104: 2705-2712

23 Zhang KD, Ajami D, Rebek J. Hydrogen-bonded capsules in water. J Am Chem Soc, 2013, 135: 18064-18066

24 Hartnig C, Witschel W, Spohr E, et al. Modifications of the hydrogen bond network of liquid water in a cylindrical $\mathrm{SiO}_{2}$ pore. J Mol Liq, 2000, 85: 127-137

25 Chalaris M, Samios J. Hydrogen bonding in supercritical methanol. A molecular dynamics investigation. J Phys Chem B, 1999, 103: 1161-1166

26 Eaves JD, Loparo JJ, Fecko CJ, et al. Hydrogen bonds in liquid water are broken only fleetingly. Proc Natl Acad Sci USA, 2005, 
102: 13019-13022

27 Hu C, Han Q, Zhao F, et al. Graphitic $\mathrm{C}_{3} \mathrm{~N}_{4}-\mathrm{Pt}$ nanohybrids supported on a graphene network for highly efficient methanol oxidation. Sci China Mater, 2015, 58: 21-27

28 Zhang P, Li J, Lv L, et al. Vertically aligned graphene sheets membrane for highly efficient solar thermal generation of clean water. ACS Nano, 2017, 11: 5087-5093

29 Si Y, Wang L, Wang X, et al. Ultrahigh-water-content, superelastic, and shape-memory nanofiber-assembled hydrogels exhibiting pressure-responsive conductivity. Adv Mater, 2017, 29: 1700339

30 Sun $\mathrm{H}, \mathrm{Xu} Z$, Gao C. Multifunctional, ultra-flyweight, synergistically assembled carbon aerogels. Adv Mater, 2013, 25: 2554-2560

31 Munson BR, Okiishi TH, Huebsch WW, et al. Fluid Mechanics. Singapore: Wiley, 2013

32 Sawhney G S. Fundamentals of Fluid Mechanics. New Delhi: IK International Pvt. Ltd., 2013

33 Zhao G, Hu R, Li J, et al. Graphene oxide quantum dots embedded polysulfone membranes with enhanced hydrophilicity, permeability and antifouling performance. Sci China Mater, 2019, 62: $1177-1187$

34 Raj R, Maroo SC, Wang EN. Wettability of graphene. Nano Lett, 2013, 13: 1509-1515

35 Nicolas JP, Smit B. Molecular dynamics simulations of the surface tension of $n$-hexane, $n$-decane and $n$-hexadecane. Mol Phys, 2002, 100: $2471-2475$

36 Moultos OA, Tsimpanogiannis IN, Panagiotopoulos AZ, et al. Atomistic molecular dynamics simulations of carbon dioxide diffusivity in $n$-hexane, $n$-decane, $n$-hexadecane, cyclohexane, and squalane. J Phys Chem B, 2016, 120: 12890-12900

37 Surblys D, Yamaguchi Y, Kuroda K, et al. Molecular dynamics analysis on wetting and interfacial properties of water-alcohol mixture droplets on a solid surface. J Chem Phys, 2014, 140: 034505

38 Noskov SY, Lamoureux G, Roux B. Molecular dynamics study of hydration in ethanol-water mixtures using a polarizable force field. J Phys Chem B, 2005, 109: 6705-6713

39 Li Q, Xiao Y, Shi X, et al. Rapid evaporation of water on graphene/ graphene-oxide: A molecular dynamics study. Nanomaterials, 2017, 7: 265

40 Argyris D, Tummala NR, Striolo A, et al. Molecular structure and dynamics in thin water films at the silica and graphite surfaces. J Phys Chem C, 2008, 112: 13587-13599

41 Huang Y, Cheng H, Yang C, et al. Interface-mediated hygroelectric generator with an output voltage approaching 1.5 volts. Nat Commun, 2018, 9: 4166

42 Marčelja S, Mitchell DJ, Ninham BW, et al. Role of solvent structure in solution theory. J Chem Soc Faraday Trans 2, 1977, 73: 630-648

43 Luzar A, Chandler D. Structure and hydrogen bond dynamics of water-dimethyl sulfoxide mixtures by computer simulations. J Chem Phys, 1993, 98: 8160-8173

44 Roger K, Liebi M, Heimdal J, et al. Controlling water evaporation through self-assembly. Proc Natl Acad Sci USA, 2016, 113: 1027510280

Acknowledgements This work was supported by the Ministry of Science and Technology of China (2016YFA0200200 and 2017YFB1104300), the National Science Foundation of China (51673026, 51433005 and 21805160), NSFC-MAECI (51861135202), NSFC-STINT (21911530143), and Beijing Natural Science Foundation
(2152028). Computations were carried out on the "Explorer 100" cluster system of Tsinghua National Laboratory for Information Science and Technology.

Author contributions $\quad \mathrm{Qu} \mathrm{L}$ and Zhang $\mathrm{P}$ designed the experiments; Zhang P, Liao Q, Yao H and Wang D performed the experiments; Xu Q, $\mathrm{Ma} \mathrm{T}$ and Liao Q conducted the computational studies; Cheng H, Li C, Yao $\mathrm{H}$ and Geng $\mathrm{H}$ gave advice on experiments; Qu L supervised the entire project. All authors discussed the results and reviewed the manuscript.

Conflict of interest The authors declare that they have no conflict of interest.

Supplementary information Experimental details and supporting data are available in the online version of the paper.

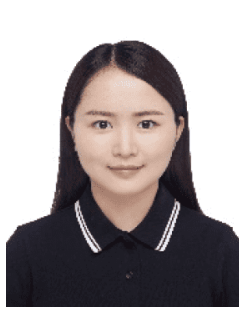

Panpan Zhang received her MSc degree from Beijing Institute of Technology in 2017. She is now a $\mathrm{PhD}$ student under the supervision of Prof. Liangti Qu at Tsinghua University, focusing on the solar-driven interfacial evaporation for water purification.

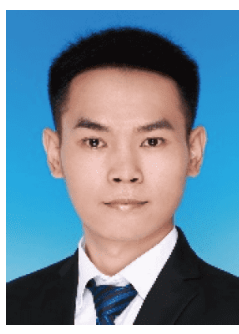

Qiang Xu received his $\mathrm{BE}$ degree from the Northwest A\&F University in 2015 and MSc degree from Beijing Institute of Technology in 2018. He is now a $\mathrm{PhD}$ student at Tsinghua University. At present, his research focuses on the surface-interface properties and tribology of solid material based on theoretical simulation.

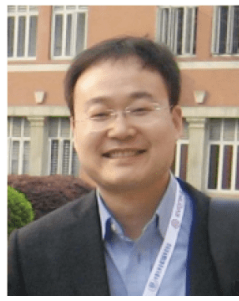

Liangti $\mathrm{Qu}$ received a $\mathrm{PhD}$ degree in chemistry from Tsinghua University (China) in 2004. He is now a Changjiang professor with research focusing on carbon-based/polymer-based advanced functional materials and energy-related devices.

\section{基于排列有序石墨烯膜材料的界面增强蒸馏}

张盼盼 ${ }^{1 \dagger}$, 徐强 ${ }^{1 \dagger}$, 廖启华 ${ }^{1}$, 姚厚泽 ${ }^{1}$, 王德斌, 耿洪亚 ${ }^{2}$, 程虎虎 ${ }^{1}$, 李春 $^{2}$,马天宝 ${ }^{1}$, 曲良体 ${ }^{1,2^{*}}$

摘要 用于化学工业中液体分离和纯化的传统蒸馏是一种高能 耗、低效率的方法. 本文制备了排列有序的石墨烯膜材料作为液 体表面的蒸发层用于界面增强蒸馏. 该界面增强蒸馏增大了蒸发 面积, 削弱了溶液中分子在石墨烯膜材料表面(液/固/气界面)的分 子间作用力, 从而可加快蒸发速率, 降低能耗, 节约时间, 甚至实现 了低于沸点温度下馏分的收集. 